\title{
Making copies of religious culture relics using reverse engineering
}

\author{
Kopiowanie zabytków kultury sakralnej \\ z zastosowaniem inżynierii odwrotnej
}

\section{BARTOSZ PIERÓG KRZYSZTOF FILIPOWICZ MIROSŁAW PAJOR*}

DOI: https://doi.org/10.17814/mechanik.2020.4.10
Presented is the process of making copies of reliefs that are religious culture relics. Described is making of two replacements of exhibits from West Pomeranian churches. Priceless relics were made available courtesy of the National Museum in Szczecin that poses them in its collection. Sculptures were scanned using a contactless method with an industrial 3D scanner. Obtained data were used to develop technology and make copies using five-axis milling centre to achieve a satisfying reconstruction of details. Copies were made during realisation of a master project on Mechanics and Machines Making studies in Mechanical Engineering and Mechatronics department of the West Pomeranian University of Technology in Szczecin. Achieved effects were, on one hand, the copies and on the other hand, the enrichment of the didactic process with practical experience, necessary in technical studies.

KEYWORDS: reverse engineering, relics, multi-axis machining

Opisano proces kopiowania płaskorzeźb będących zabytkami kultury sakralnej. Omówiono wykonanie dwóch zastępczych eksponatów pochodzących z kościołów z Pomorza Zachodniego. Bezcenne zabytki zostały udostępnione przez Muzeum Narodowe w Szczecinie, w którego zbiorach się znajdują. Rzeźby zeskanowano metodą bezdotykową z użyciem przemysłowego skanera 3D. Na podstawie uzyskanych danych opracowano technikę wykonania kopii na pięcioosiowym centrum frezarskim, które dawało gwarancję satysfakcjonującego odwzorowania szczegółów. Wykonanie kopii było elementem pracy dyplomowej na kierunku Mechanika i Budowa Maszyn na Wydziale Inżynierii Mechanicznej i Mechatroniki Zachodniopomorskiego Uniwersytetu Technologicznego w Szczecinie. Dzięki temu oprócz wykonania kopii eksponatów osiągnięto efekt w postaci wzbogacenia procesu dydaktycznego o niezbędne w toku studiów technicznych doświadczenia praktyczne.

SŁOWA KLUCZOWE: inżynieria odwrotna, zabytki, obróbka wieloosiowa

\section{Wprowadzenie}

W ramach współpracy między Wydziałem Inżynierii Mechanicznej i Mechatroniki Zachodniopomorskiego Uniwersytetu Technologicznego w Szczecinie a Muzeum Narodowym w Szczecinie pojawiła się potrzeba wykonania kopii eksponatów, aby umożliwić zapoznanie się z nimi osobom niewidomym. Dobrym rozwiązaniem okazało się w tym przypadku zastosowanie inżynierii rekonstrukcyjnej, nazywanej również inżynierią odwrotną (reverse engineering), która oferuje narzędzia pozwalające zrealizować ścieżkę: model wyrobu $\rightarrow$ zapis elektroniczny (model wirtualny) $\rightarrow$ wyrób [1].

Wytypowano dwie płaskorzeźby, należące do najstarszych wytworów sztuki sakralnej z rejonu Pomorza Zachodniego. Są to Maria z Dzieciątkiem z Gardna, datowana na XIII w., oraz płaskorzeźba przedstawiająca apostołów Pawła, Tomasza i Jakuba Starszego z Dąbia, datowana na XVI w. (rys. 1).
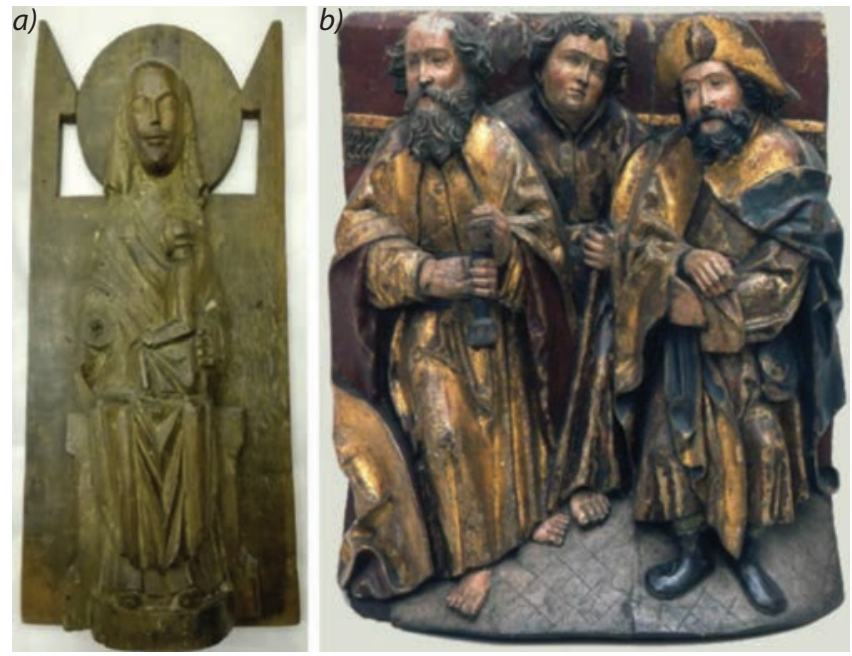

Fig. 1. Original exhibits: $a$ ) Maria and the Child, $b$ ) bas-relief depicting the apostles Paul, Thomas and Jacob the Elder

Rys. 1. Oryginalne eksponaty: a) Maria z Dzieciątkiem, b) płaskorzeźba przedstawiająca apostołów Pawła, Tomasza i Jakuba Starszego

\footnotetext{
* Mgr inż. Bartosz Pieróg, bartek.pierog@gmail.com - Zachodniopomorski Uniwersytet Technologiczny w Szczecinie, Wydział Inżynierii Mechanicznej i Mechatroniki, Szczecin, Polska

Dr inż. Krzysztof Filipowicz, kfilipowicz@zut.edu.pl, https://orcid.org/0000-0001-6923-6669 - Zachodniopomorski Uniwersytet Technologiczny w Szczecinie, Wydział Inżynierii Mechanicznej i Mechatroniki, Szczecin, Polska

Dr hab. inż. Mirosław Pajor, prof. ZUT, mpajor@zut.edu.pl, https://orcid.org/0000-0002-7701-385X - Zachodniopomorski Uniwersytet Technologiczny w Szczecinie, Wydział Inżynierii Mechanicznej i Mechatroniki, Szczecin, Polska
} 
Ponieważ wybrane eksponaty są cenne, do ich digitalizacji użyto przemysłowego skanera bezdotykowego ATOS firmy GOM. Oprogramowanie tego skanera pozwala na automatyczną triangulację otrzymanej chmury punktów, dzięki czemu uzyskano powierzchnię $w$ formacie STL. Jest to standardowy format, w którym zapisuje się wyniki skanowania. Ma on postać zbioru punktów, na których tworzona jest trójkątna siatka poprzez połączenie trzech sąsiednich punktów [3]. Format ten jest również szeroko stosowany $\mathrm{w}$ technikach szybkiego prototypowania, jednak ze względu na niedoskonałości tych technik w opisywanym przypadku zdecydowano się zastosować klasyczne metody obróbki ubytkowej.

Powierzchnię uzyskaną dzięki skanowaniu trzeba odpowiednio przygotować, by mogła stanowić podstawę do opracowania techniki wykonania. Przede wszystkim taka powierzchnia jest odtwarzana z dużej liczby punktów, niejednokrotnie znajdujących się blisko siebie. Tak dużych zbiorów nie da się bezpośrednio wykorzystać we współczesnych systemach CAD [2]. Ponadto automatyczne przetwarzanie uzyskanych geometrii niejednokrotnie powoduje powstanie błędów w tworzonych powierzchniach, co również utrudnia, a nawet uniemożliwia ich użycie w dalszych pracach.

\section{Opracowanie techniki}

Po konsultacji z kustoszem Muzeum Narodowego w Szczecinie zdecydowano, że materiał, z którego zostaną wykonane kopie, powinien być podobny w dotyku do drewna, z którego są zrobione oryginalne dzieła. Z uwagi na niejednorodną strukturę oraz aby zapewnić trwałość kopii, zdecydowano o zastosowaniu płyt modelarskich o średniej gęstości. Jest to materiał łatwo obrabialny, przeznaczony do wykonywania form do laminacji oraz modeli formierskich.

Ze względu na gabaryty wykonywanych przedmiotów takie cechy jak łatwość obróbki i jednorodność przemawiają na korzyść wybranego materiału. Dodatkowo niewielka odporność mechaniczna materiału ogranicza skutki ewentualnych kolizji, mogących wystąpić podczas realizacji projektu w ramach procesu dydaktycznego.

Procedury obróbkowe opracowano w programie SolidCam, który pozwala na programowanie maszyn wieloosiowych i jest przystosowany do pracy z geometrią w formacie STL. Dzięki temu program sprawnie działa, nawet jeśli wystąpią niewielkie niedoskonałości powierzchni i gdy pliki są duże.

Do realizacji obróbki wybrano centrum frezarskie DMU 60T, które jest dostępne w hali technologicznej uczelni. Przy wyborze maszyny kierowano się tym, że pełna obróbka wymaga dostępu do modelu z kilku stron, dlatego konieczne jest zastosowanie więcej niż trzech osi sterowanych. Podczas obróbki na maszynie trzyosiowej konieczna byłaby zmiana mocowania detalu, co mogłoby pogorszyć jakość operacji, a także dokładność odwzorowania.

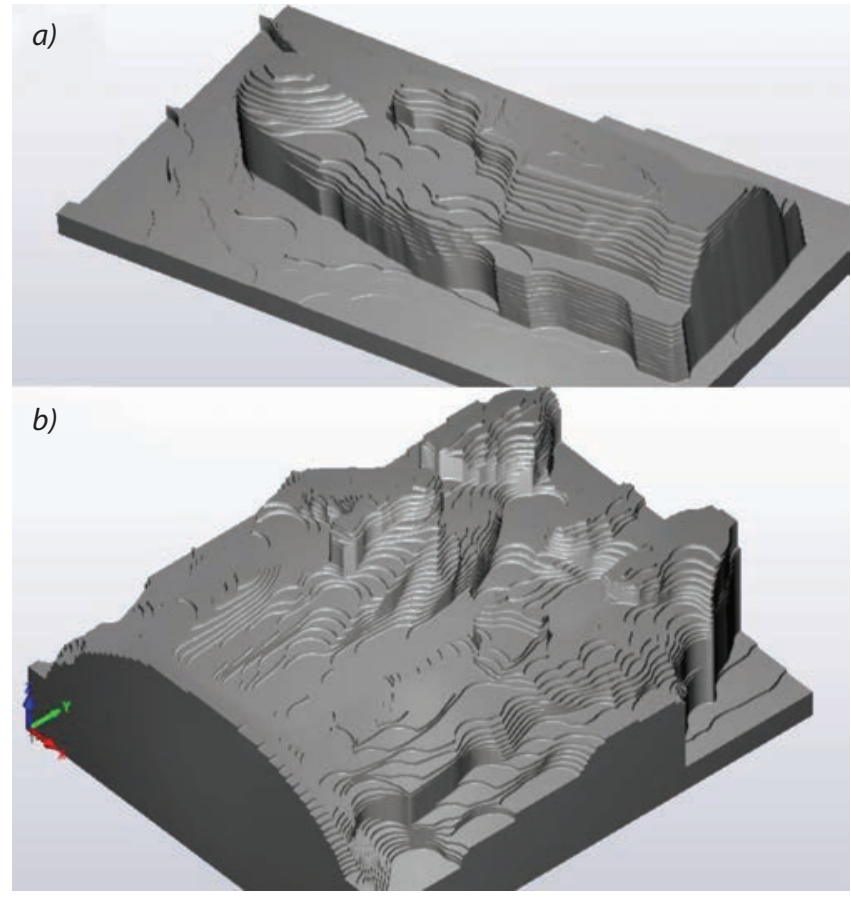

Fig. 2. Copies after simulation of roughing with a $\varnothing 40 \mathrm{~mm}$ milling cutter: a) Maria and the Child, b) bas-relief depicting the apostles Paul, Thomas and Jacob the Elder

Rys. 2. Kopie po symulacji obróbki zgrubnej frezem $\varnothing 40 \mathrm{~mm}$ : a) Maria z Dzieciątkiem, b) płaskorzeźba przedstawiająca apostołów Pawła, Tomasza i Jakuba Starszego

Do obróbki zgrubnej wybrano frez promieniowy o średnicy $\varnothing 40 \mathrm{~mm}$ i promieniu naroża $1,6 \mathrm{~mm}$, przeznaczony do pracy z wysokimi posuwami.

W miejscach niedostępnych dla takiego narzędzia, w których konieczne było usunięcie dużych ilości materiału, przeprowadzono dodatkowe operacje frezem kulowym o średnicy $\varnothing 8 \mathrm{~mm}$. Przykłady takich miejsc przedstawiono na rys. 3 i 4.

Takim samym frezem wykonano obróbkę wykończeniową większości powierzchni, a tam gdzie było konieczne uzyskanie mniejszego promienia, użyto frezu kulowego o średnicy $\varnothing 3 \mathrm{~mm}$. Zastosowanie frezów kulowych umożliwiło uzyskanie dobrej jakości powierzchni obrabianej przez wykorzystanie strategii wierszowania w różnych kierunkach.

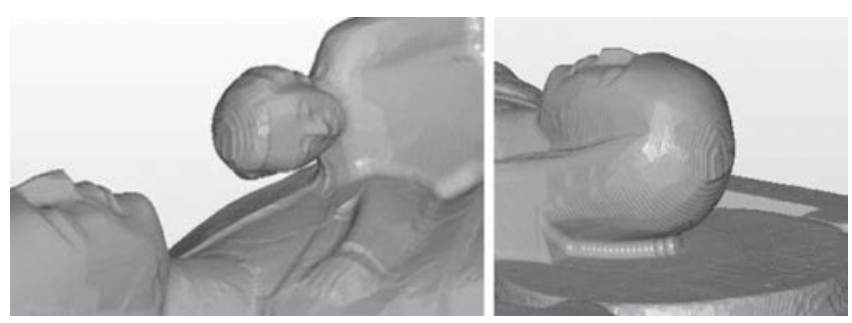

Fig. 3. Hardly accessible places in the bas-relief of Mary and the Child Rys. 3. Trudno dostępne miejsca w płaskorzeźbie Marii z Dzieciątkiem

Należy zwrócić uwagę, że w prezentowanych rzeźbach jest wiele powierzchni wklęsłych i takich, do których dostęp jest możliwy jedynie z zastosowaniem długiego narzędzia i obróbki od spodu. Niejednokrotnie nawet to nie dawało efektu i aby zapewnić satysfakcjonujące efekty, trzeba było przewidzieć obróbkę z kilku kierunków. 

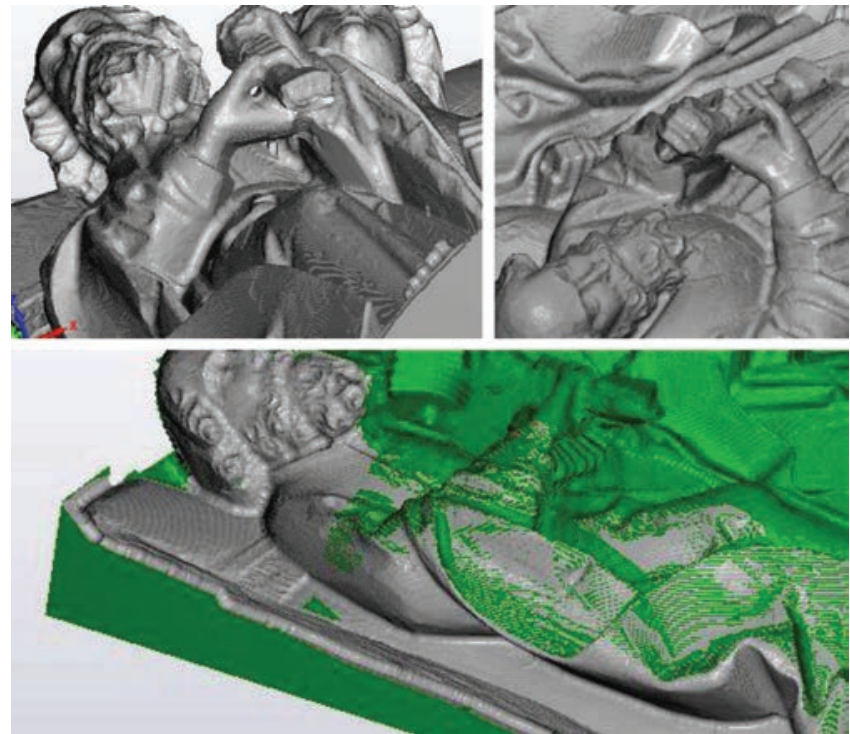

Fig. 4. Hard to reach places in a bas-relief depicting the apostles Paul, Thomas and Jacob the Elder

Rys. 4. Trudno dostępne miejsca w płaskorzeźbie przedstawiającej apostołów Pawła, Tomasza i Jakuba Starszego

W technice wykonania przewidziano bardzo długie narzędzia, umożliwiające obróbkę takich kłopotliwych miejsc. Niestety na rynku nie ma wystarczająco długich narzędzi. Konieczne było zastosowanie tulei przedłużającej o średnicy $\varnothing 16 \mathrm{~mm} \mathrm{z}$ gniazdem na tulejki zaciskowe ER16, umożliwiającym chwytanie narzędzi o średnicy do $\varnothing 8 \mathrm{~mm}$. To zapewniło wystarczający wysięg narzędzia przy minimalnym ryzyku kolizji.

Opracowywanie techniki w programie CAM pozwala na przeanalizowanie przewidywanych niedokładności obróbki i ewentualne wprowadzenie poprawek w miejscach, gdzie jest to konieczne. Analiza przewidywanych resztek naddatku została przedstawiona na rys. 5 i 6 . Czerwonym kolorem oznaczono na modelu miejsca, gdzie w porównaniu z powierzchnią docelową pozostał nieusunięty naddatek.

Nieusunięte resztki pojawiły się przede wszystkim $\mathrm{w}$ miejscach, gdzie występują niewielkie promienie wewnętrzne, i dlatego konieczne jest wykonanie poprawek z użyciem małych narzędzi. W związku z tym ostateczną weryfikację efektów obróbki należało przeprowadzić już na modelu fizycznym i ewentualnie wprowadzić dodatkowe operacje w miejscach, gdzie faktycznie efekt nie byłby zadowalający.

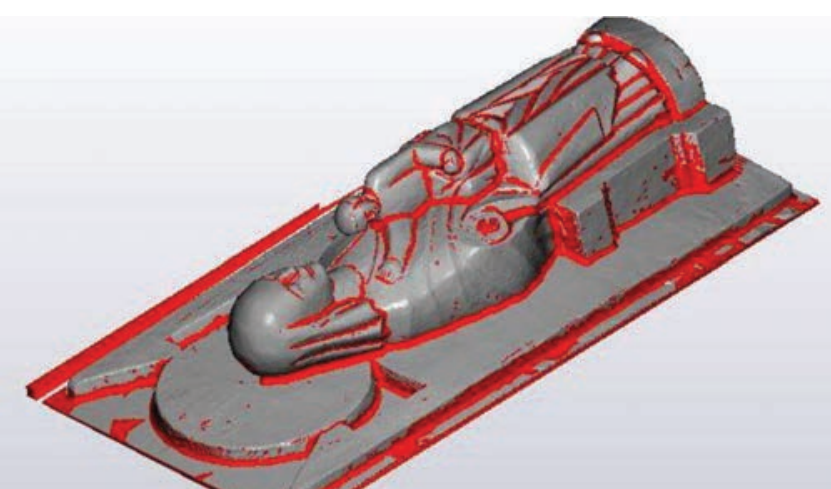

Fig. 5. Residual allowance analysis on the bas-relief of Mary and the Child

Rys. 5. Analiza resztek naddatku na płaskorzeźbie Marii z Dzieciątkiem

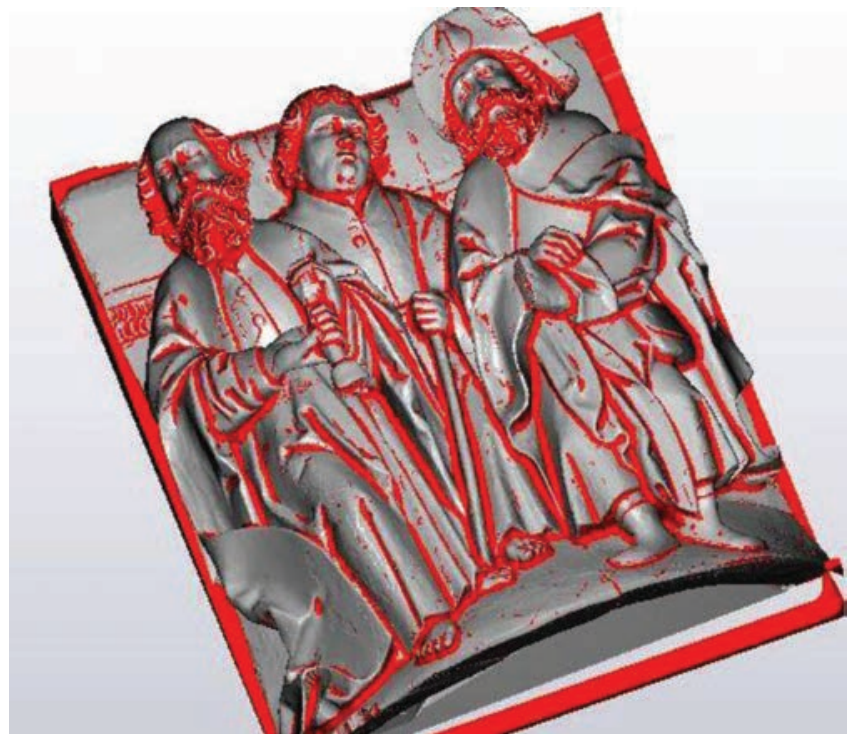

Fig. 6. Residual allowance analysis on a bas-relief depicting the apostles Paul, Thomas and Jacob the Elder

Rys. 6. Analiza resztek naddatku na płaskorzeźbie przedstawiającej apostołów Pawła, Tomasza i Jakuba Starszego

\section{Realizacja obróbki}

Obróbka na centrum frezarskim przebiegała zgodnie z zaplanowaną strategią. Trzeba jednak było zmodyfikować program niektórych operacji, aby zapewnić bezpieczne przejazdy długimi narzędziami.

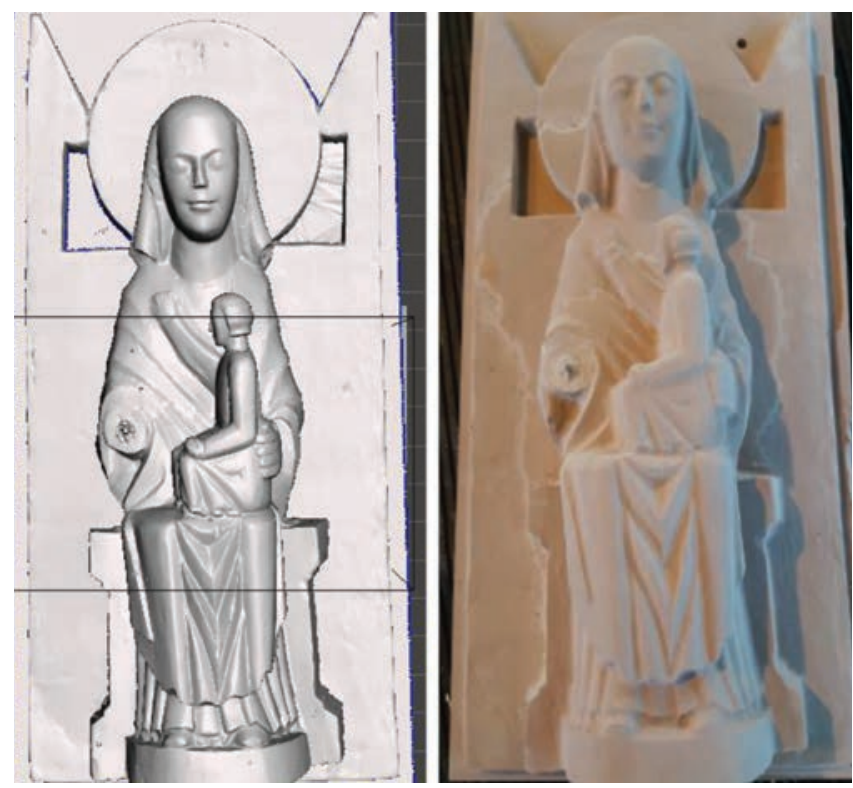

Fig. 7. Comparison of the copy of the bas-relief of Mary and the Child with the surface obtained by scanning

Rys. 7. Porównanie kopii płaskorzeźby Marii z Dzieciątkiem z powierzchnią uzyskaną przez skanowanie

W przypadku obróbki płaskorzeźby przedstawiającej apostołów konieczny był podział zarówno obróbki zgrubnej, jak i wykończeniowej na dwa etapy, by wykorzystać powiększoną przestrzeń roboczą obrabiarki. W centrum frezarskim zainstalowano stół obrotowy. Jego obrót o $180^{\circ}$ pozwala na obróbkę w dwukrotnej długości jednej z osi liniowych.

Na rys. 7 i 8 zestawiono efekty obróbki z modelami powierzchniowymi uzyskanymi po skanowaniu oryginalnych eksponatów. 

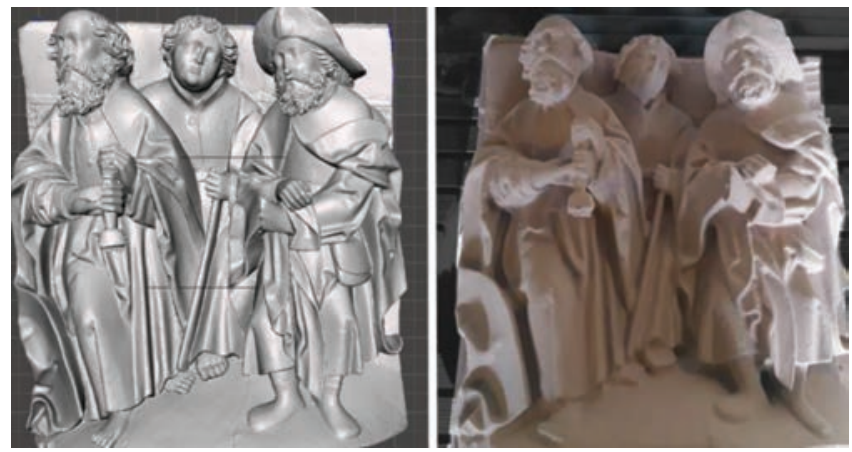

Fig. 8. Comparison of the copy of the bas-relief depicting the apostles Paul, Thomas and Jacob the Elder with the surface obtained by scanning

Rys. 8. Porównanie kopii płaskorzeźby przedstawiającej apostołów Pawła, Tomasza i Jakuba Starszego z powierzchnią uzyskaną przez skanowanie

\section{Podsumowanie}

Podczas realizacji projektu wykorzystano szerokie możliwości inżynierii odwrotnej. Digitalizacja modeli, jako pierwszy etap, ma kluczowe znaczenie dla poprawności wykonania całego przedsięwzięcia. Istotne przed przystąpieniem do kolejnych etapów są filtracja i edycja chmur punktów oraz maksymalne zmniejszenie rozmiaru pliku. Wpływa to na znaczne przyspieszenie obliczeń w programie CAM.

W omawianym projekcie niezbędną funkcją programu CAM jest możliwość opracowania procesu technologicznego na podstawie pliku STL jako modelu docelowego. Także wykonanie symulacji jest bar- dzo przydatne, ponieważ pozwala na wstępną ocenę uzyskanych efektów i wprowadzenie ewentualnych zmian w celu wyboru optymalnego rozwiązania. Niewątpliwą zaletą modułu symulacji jest weryfikacja kolizji przygotówki i narzędzia, ale równie ważna jest możliwość analizy resztki materiału oraz oszacowania czasu operacji. Prawidłowy dobór strategii pozwala skrócić czas pracy na obrabiarce.

Z analizy techniki obróbki kopii płaskorzeźb wyni$\mathrm{ka}$, że ich wykonanie wymaga przeprowadzenia wielu skomplikowanych operacji. Jest to związane z występowaniem dużej liczby trudno dostępnych miejsc.

Ze względu na charakter przedmiotów obrabianych ocena uzyskanych efektów jest bardzo trudna, bo wymaga uwzględnienia subiektywnych wrażeń. Ponowne skanowanie wykazało, że odległości między powierzchnią uzyskaną a teoretyczną powierzchnią przedmiotu nie przekraczają $0,5 \mathrm{~mm}$.

\section{LITERATURA}

[1] Karbowski K. „Podstawy rekonstrukcji elementów maszyn i innych obiektów w procesach wytwarzania". Kraków: Politechnika Krakowska, 2008, ISSN 0860-097X.

[2] Kachel S., Kozakiewicz A., Łacki T., Olejnik A. "Zastosowanie inżynierii odwrotnej do procesu odtwarzania geometri układu wlotowego silnika RD-33 w samolocie MIG-29". Prace Instytutu Lotnictwa Wojskowej Akademii Technicznej. 213 (2011): 66-84

[3] Wróbel I. „Inżynieria odwrotna jako metoda tworzenia cyfrowych modeli przedmiotów o skomplikowanych kształtach". Mechanik. 83, 3 (2010): 212-214

[4] Migacz M., Kwaczyński W., Nazzal A. „Inżynieria odwrotna w modelowaniu powierzchni krzywoliniowych". Mechanik 76, 12 (2003): 741-744.

[5] www.solidcam.com/pl/ (dostęp: 02.03.2020 r.). 